\title{
Prospects and Challenges of Implementing Enterprise Mobility Management - Case of a Large Telecom Service Provider in
}

\section{United Arab Emirates}

Syed Mubashir Ali ${ }^{1}$, Muhammad Usman ${ }^{2}$

${ }^{1}$ Department of Computing, Shaheed Zulfiqar Ali Bhutto Institute of Science and Technology - SZABIST, Dubai, United Arab Emirates

mubashir8733@gmail.com

${ }^{2}$ Mobility Consultant, Sybase Products Middle East, Dubai, United Arab Emirates muhammad.usman@sybase.ae

\section{ABSTRACT}

Over the last few years, there has been an exponential rise in the trend of using mobile devices within enterprises. Organizations and employees are using their smart phones and tablets to aid in work. Several organizations have introduced the concept of "bring your own device" (BYOD) in order to achieve more efficiency and improved productivity. This increase in use of mobile devices, although providing benefits to the organizations, is also resulting in more effort for the information technology (IT) staff to provide support and manage these devices within the enterprise. Several organizations around the globe are implementing mobile device management (MDM) / enterprise mobility management (EMM) solutions to manage mobile devices within the organization. This study identifies the prospects and challenges in implementing EMM using a case of a large telecom service provider in United Arab Emirates (UAE).

\section{Keywords}

BYOD, Enterprise Mobility Management, Mobile Device Management, MDM, UAE.

\section{Council for Innovative Research}

Peer Review Research Publishing System

Journal: INTERNATIONAL JOURNAL OF COMPUTERS \& TECHNOLOGY

Vol 10, No 8.

editor@cirworld.com

www.cirworld.com, member.cirworld.com 


\section{INTRODUCTION}

Over the past decade, there has been an exponential increase in the use of mobile devices.[3] Enterprises, previously using and dependent upon desktop computers have been transitioning to laptops and mobile devices. [5] According to [4], statistics have revealed that 48 percent of smartphone users make use of their mobile devices to assist their work. This increase in the use of mobile devices in workplace has raised problems and increased effort for the IT staff to support and manage these devices. Enterprise Mobility Management (EMM) is the set of people, processes and technology focused on managing the increasing array of mobile devices, wireless networks, and related services to enable broad use of mobile computing in a business context. This is an emerging discipline within the enterprise that has become increasingly important over the past few years as more workers have bought smart phone and tablet computing devices and have sought support for using these devices in the workplace. This paper using the case of a large telecom service provider outlines the prospects and challenges in implementing EMM. The first section has given the introduction to this study. Section 2 provides a brief background of the case company. Section 3 highlights the challenges and issues in implementing EMM. Section 4 will outline the benefits of implementing EMM. The last section summarizes and concludes this study.

\section{COMPANY BACKGROUND}

Etisalat is a leading telecom service provider and the first to start its operations in the UAE, [2] is operating in more than 15 countries in the Middle East and Africa (MENA) region [1] and is one of the biggest enterprises among the countries in the Gulf Cooperation Council (GCC). It has a market value of approximately Dh81 billion (US\$22 billion) and annual revenues of over Dh32.9 billion (US\$9 billion). [1] Currently, Etisalat has directly employed approximately 42000 staff. [1] Etisalat being the leader in providing communication and broadband service and having a large IT infrastructure is highly dependent on information technology (IT). The company has more than 5000 employees in UAE and almost all of them using their smartphones at workplace were facing problems in managing these mobile devices. As a result, the company decided to implement EMM in order to manage the mobile devices being used within the organization.

\section{CHALLENGES AND ISSUES}

The second author has been associated with Etisalat as mobility consultant for the implementation of EMM. The author had been involved in several meetings and discussions with the company's stakeholders including top management and IT staff for the implementation of the project. Several issues and challenges were being identified as the result of discussions and meetings through the past experience of the author in EMM implementation and empirical evidences. The issues being identified are being classified into following categories:

\section{Social Issues}

One of the most important challenges in implementing mobile device management is the public awareness for the use of managing the devices and securing the data and performing the segregation of personal and corporate data. Majority of the population in UAE is accustomed to changing to new smart phones and mobile devices with the advancement in technology and availability of new smartphones in the market. Rapid change of the mobile devices makes the data residing in the smartphones highly vulnerable, as an employee might sell his old device without caring to remove the corporate and confidential data and information from his/her mobile device. Also a number of mobile device users do not feel comfortable with this technology for managing their devices and data so as to enable protection against the unauthorized access.

\section{Technological Issues}

The main issue faced while implementing the mobile device management for the corporate is the expansion of network infrastructure and enabling all the devices to use data networks when not in range of the Wi-Fi networks. The corporate $\mathrm{Wi}-\mathrm{Fi}$ also required expansion and a wider coverage. A dedicated team of experienced professionals were required to work on the EMM administrator console and work on creating the policies and groups for managing mobile devices. Employees using their personal devices need to be managed separately in different groups where segregation of data is performed between the personal and corporate data. Because of the requirement of huge number of devices, the server environment has to be made highly available by installing server farm environment. Another challenge was to train the IT staff of the company with the use of device management console to design basic and complex policies for the mobile devices used within the network. Also, the company had a large number of employees having mobile devices which made the enrollment of all the devices in the EMM a big challenge.

\section{BENEFITS OF IMPLEMENTING ENTERPRISE MOBILITY MANAGEMENT}

There are a number of benefits of implementing EMM within an enterprise. The benefits resulted from the implementation of EMM for Etisalat are as follows:

\section{Data and Information Security}

The major benefit of implementing EMM is the security of data and information residing in the mobile devices. Mobile devices are prone to being lost or stolen; corporate confidential data on those devices is highly vulnerable. When corporate data is accessible via a personal mobile device, organizations suddenly lose a great deal of control over who can access that data. An Enterprise mobility management system helps in prevention of unauthorized access to enterprise 
applications and/or corporate data on mobile devices. These can include password protection; encryption and/or remote wipe technology, which allows an administrator to delete all data from a misplaced device. With EMM systems, security policies can be centrally managed and enforced. Such device management systems are programmed to support and cooperate with the application programming interfaces (APIs) from various device makers to increase security compliance without increased labor.

\section{Application Management}

System administrators cannot expect to have the same access to mobile device clients as they would have to desktop devices that don't leave an office. Lack of access combines with operating system heterogeneity to make routine tasks such as deployments, configuration settings, and application installations and help desk tasks very difficult. Each device has unique management requirements and tasks often must be performed remotely, over the air. Enterprise mobility management systems generally provide middleware to automate management tasks and insulate administrators from the complexity of performing tasks on many different types of devices. It also provides infrastructure to securely administer devices over the air. Self-management portals, that allow users to download updates and applications on their own, are another common feature.

\section{Financial Management}

The cost of voice and data were once wholly contained within the walls of the enterprise. With mobile devices this is no longer the case. Often, each employee negotiates their own contract with a mobile carrier and then bills his employer for some or all of these costs as a reimbursement, creating budget unpredictability for the organization. Enterprise mobility management addresses this issue and includes telecom expense management features that help organizations plan for and control the overall costs of mobile voice and data transmissions. Other tasks such as carrier contract negotiations, invoice processing and/or device requisition costs, when appropriate, can also be included.

\section{CONCLUSION}

It has been evident, that implementing a technology based solution give rise to some issues that needs to be addressed for that IT project to be a success.[6] The challenges identified in this study may be applicable to other industries around the globe, but this study mainly focused on the scenario of organizations in UAE. The same with the benefits, as there can be many more benefits for using EMM, but the benefits that were expected and resulted after the implementation at Etisalat are being outlined in this paper. Further study can be done on the organizations in other parts of the world to perform a comparative study of the differences in the challenges faced and resulting benefits of implementing EMM.

\section{ACKNOWLEDGMENTS}

Authors would like to acknowledge Ms. Yusra Nisar for proofreading of this paper.

\section{REFERENCES}

[1] Etisalat Company Profile, http://www.etisalat.com/en/about/profile/company-profile.jsp. (Accessed on August 5, 2013)

[2] http://www.khaleeitimes.com/kt-article-display1.asp?xfile=data/uaebusiness/2013/June/uaebusiness June31.xml\&section=uaebusiness. (Accessed on August 5 , 2013)

[3] World Economic Forum, Global IT report, 2012. http://www3.weforum.org/docs/Global IT Report 2012.pdf.

[4] MacCormick, J. S., Dery, K., \& Kolb, D. G.. Engaged or just connected? Smartphones and employee engagement. Organizational Dynamics, 41(3), 2012, 194-201.

[5] Ali, S. M, Challenges and security issues in future IT infrastructure components. International Journal of Computers \& Technology, 8(2), 2012, 845-847.

[6] Ali, S. M. Challenges and Benefits of Implementing Tablets in Classroom for e-Learning in a K-12 Education Environment - Case Study of a School in United Arab Emirates, Research Inventy: International Journal of Engineering and Science, 3(4), 2013, 39-42. 


\section{Author' biography with Photo}

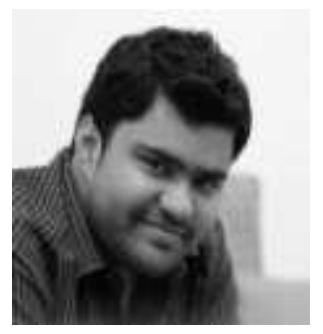

Syed Mubashir Ali has completed his BS in Computer Engineering from National University of Computer and Emerging Sciences - FAST, Karachi, Pakistan. Currently he is enrolled in MS Computing in IT at Shaheed Zulfiqar Ali Bhutto Institute of Science and Technology, SZABIST, Dubai, United Arab Emirates. His research interest includes IT infrastructure, Cloud computing, Standardization of IT, IT governance, E-Learning, Enterprise resource planning and IT performance measurement.

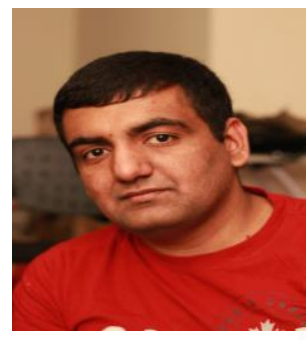

Muhammad Usman is working as a Technical Consultant for Mobility Solutions at Sybase Products Middle East. And is pursuing Masters in Information Technology as part time. His Research interest includes mobility, enterprise resource planning and technology standards. 